Seeing the invisible: Extracting signs of depression and suicidal ideation from college students' writing using LIWC a computerized text analysis

Lumontod, Robinson Z., III $\$
Central Luzon State University, Philippines (robinsonlumontodiii@gmail.com)

Received: 30 January 2020

Available Online: 29 June 2020
Revised: 4 April 2020 DOI: $10.5861 /$ ijrse.2020.5007

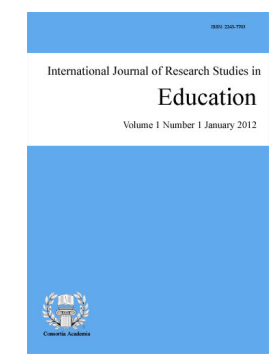

ISSN: $2243-7703$ Online ISSN: 2243-7711

OPEN ACCESS

\title{
Abstract
}

Depression remains one of the leading problems around the world. Partly, the problem stems from the fact that depression is still difficult to diagnose using traditional assessment tools. A few pieces of evidence suggest that text analysis is capable of identifying psychological states and mental issues including depression. However, this method has not been tested in the Philippines. The main purpose of this study, therefore, was to determine clues of depression and suicidal ideation in college students' writing using the online version of LIWC, a computerized text analysis. The present study was conducted at Central Luzon State University, Philippines where 159 undergraduate students participated. Using correlational analysis, several important findings were found. First, college students with a high level of depression and suicidal ideation tend to write more personal pronouns such as "I", "me", and "my" in their writing. Second, LIWC traditional dimensions such as I-words and negative emotions show a significant link with depression but only the I-words dimension was significantly associated with suicidal ideation. Third, LIWC summary variables such as clout and emotional tone also show a significant relationship with depression and suicidal ideation. Furthermore, regression analysis suggests that these LIWC domains were significant predictors of depression. However, only emotional tone was found to have a modest but significant influence on suicidal ideation. Lastly, the length of the essay was significantly correlated with depression but not with suicidal ideation. The theoretical and practical implications of the findings are discussed.

Keywords: depression; suicidal ideation; LIWC; text analysis; college students 


\section{Seeing the invisible: Extracting signs of depression and suicidal ideation from college students' writing using LIWC a computerized text analysis}

\section{Introduction}

Depression is a worldwide epidemic that affects the large percentage of the population. The prevalence of depression is far more increasing in student population around the world. In fact, in Africa alone, almost half of the student population suffer from depression (Tam, Lo, \& Pachero, 2018). The number can be even more alarming around the world. Unfortunately, only a small percentage received the appropriate intervention. The sheer amount of help received by the affected ones might stem from two main issues; (a) because depression is, in most cases, invisible. In effect, any effort to examine the number of people affected by depression is often inaccurate. As a result, the available data on depression is only the tip of the iceberg. More students are affected than the reported number (Rotenstein, et al., 2016). This leads educators and mental health professionals unable to respond to the problem effectively. Even school records could not accurately assess depression (Kuo, Stoep, Herting, Grupp, \& McCauley, 2013). As a result, many depressed students remain untreated. When this happened, suicide cases may become even more prevalent. In the Philippines for instance, suicide cases in adolescents and young adults are increasing (Quintos, 2017). On the other study, Quintos (2017) finding suggested that approximately one in every ten Filipino youth had suicidal thoughts. The reported rate of suicidal ideation in the Philippines is higher than the neighboring Asian counties such as Malaysia where only $6.3 \%$ were reported to have suicide ideation (Maniam et al., 2013). Previous studies had provided clues on the current psychological states of youths around the world. The need for urgent action is clear. The challenge for teachers, academicians, and school administrators is to correctly identify depressed students and give corresponding and appropriate intervention. However, the process can be extremely difficult. Partly because depression is often concealed and repressed by the bearer. Generally, because of the stigma of being labeled as "depressed" or "psychologically ill" is a significant reason why most depressed students do not truly share their psychological turmoil.

Furthermore, the other hindrance in diagnosing depression is the assessment tools being used. To date, most depression assessments rely on traditional techniques. This paper argues that, while depression assessment tools are helpful, their ability to yield accurate results is weak. Social desirability and the willingness of the participants to report their inner experience often negatively affects the participants' quantitative responses. Other techniques should be developed to complement the traditional tools. Fortunately, modern techniques are available today. One of them is text analysis. This computer-aided tool yielded promising results that could potentially guide the more accurate assessment of the psychological states. Text analysis does not rely on biased self-reports but on the themes that are prevalent in personal writings. Studies on this area, however, still dearth, especially in the Philippine setting. If personal writings could provide clues of depression and suicidal ideation, then using it as an assessment tool may lessen the increasing incidence of suicides in Filipino youths.

Text analysis, as it is commonly known, is not new. Previous studies had found how written language reflects individuals' mental state (Boyd \& Pennebaker, 2015); social status (Kacewics, Pennebaker, Davis, Jeon, \& Graesser, 2013); lies (Newman, Pennebaker, Berry, \& Richards, 2003). However, most previous studies in this field had mainly focused on the political, sociological, and pure linguistic arena. Therefore, the purpose of this study was to identify clues of depression and suicidal ideation in personal writing using text analysis.

\subsection{Significance of the study}

This paper might be the first attempt to use personal writing analysis to identify cues of depression and suicide ideation in the Philippine setting. The result of this study will greatly help not only in identifying signs of depression and suicidal ideation but also in designing new strategies in assessing psychological issues. Mental 
health professionals and educators will have an alternative way of identifying students with depression and suicidal ideation.

\section{Review of related literature}

\subsection{Language and psychological states}

For decades, researchers had shifted their focus of investigation on the importance of language in understanding psychological states. A handful of empirical efforts produced some significant contributions to understanding individuals' behavior. Consistently, the findings of the previous body of literature suggest that, indeed, words reflect the inner world of an individual. For instance, Boroditsky (2001) suggests that language could shape the individuals' thinking process. Personal stories and psychological states seem to relate to one another. Vaughn (2018) found similar interesting finding which suggests that when people think about hope, their stories reflect positive experiences. This may further imply that the spoken words hide more meanings than what they literally mean. In fact, words could reveal lies (Newman, Pennebaker, Berry, \& Richards, 2003), political ideologies (Chichoka, Bilewics, Jost, Marrouch, \& Witkowska, 2016), and political trends (Jordan, Sterling, Pennebaker, \& Boyd, 2019). Beyond politics, language also reflects students' performance in school. Pennebaker, Chung, Frazee, Lavergne, and Beaver (2014) found that the seemingly irrelevant small words may predict students' academic performance. Armed with these contentions, this paper assumes that words may also provide clues of psychological states in the Philippine context.

The previous finding showed a promising method in understanding individuals' cognitive and behavioral aspects. Understanding the hidden meanings behind the spoken and written words provide a window to a new way of discovering and/or predicting human behavior. The challenge commonly found in diagnosing depression can be remedied.

\subsection{Depression}

The prevalence of depression around the world is increasingly alarming. Unfortunately, depression not only affects the general population but more so in students. A recent study shows that almost half of the student population in Africa alone suffer from depression (Tam, Lo, \& Pachero, 2018). This might be the result of academic demands that college students constantly dealing on a daily basis. As college students progress in their academic year level, they tend to become more depressed (Horgan, Sweeney, Behan, \& McCarthy, 2016). The academic requirements for each year level may have contributed to the increase in depression level. On the other hand, Chen et al. (2015) found that students' depressive symptoms were linked to academic performance. As students become more depressed, their academic performance suffers. The effect of depression can be devastating in students' overall functioning (Nyer, et al., 2013). As per available research findings, medical students were consistently diagnosed with high depression level. In fact, they are more depressed than the general population (Dahlin, Joneborg, \& Runeson, 2005). The findings of Puthran, Zhang, Tam, and Ho (2016) also suggest that about $28 \%$ of medical students around the world suffered from depression. The disproportion between sexes was also noted. Female students have higher depression than males.

The determining factors were identified as to why medical students get depressed. The factors include poor academic status and dissatisfaction with the medical education received (Ediz, Ozcakir, \& Bilgel, 2017). Being hopeless of the situation might also cause depression among medical students (Coskun, Ocalan, Ocbe, Semiz, \& Budakoglu, 2019). The body of literature on depression suggests one thing; students' mental health is at stake. Students' mental health is dwindling and needs to be addressed appropriately (Castillo \& Schwartz, 2013). However, regardless of the population affected, appropriate assessment and intervention techniques certainly needed. As reported in many studies, depression, if not treated properly may result in several psychological issues, especially in college students. One of which is suicidal ideation. 


\subsection{Suicidal ideation}

Suicidal ideation is one of the byproducts of depression. In fact, depression symptoms were found to have a significant link with suicide ideation among college students (Garlow et al., 2008). Previous studies had identified risk factors of suicide ideation. One study found that depressive symptoms and feelings of hopelessness both predict suicide ideation (Lamis, Ballard, May, \& Dvorak, 2016). However, social support is a moderating factor that moderates the relationship between depressive symptoms and hopelessness in influencing suicidal ideation. Previous studies, on the other hand, found important findings. Dissatisfaction in daily living seems to be a predictor of suicidal thoughts. Tan, Xia and Reece (2016) argued that the standard of living was associated with suicidal ideation. Much like depression, suicide ideation is shaped by contextual dynamics. However, social context is a macro factor that oftentimes more complicated to apply in making sense as to why people have developed suicidal thoughts. Fortunately, previous studies had explored different factors that are also predictors of suicide ideation. Most of the identified factors are behavioral and psychological. For instance, Dunn, Goodrow, Givens, and Austis (2008) suggest that substance abuse and suicidal ideation did have a significant link. Delfabbro, Mavaso, Winefield, and Winefield (2015) found that smoking, romantic relationship and poor health predict suicide ideation.

Aside from the behavioral factors, the thinking process also found to be a risk factor of suicide ideation. The previous study of Teismann and Forkmann (2015) reflects that the mere perception of entrapment may predict suicide ideation. Although depression is a strong predictor of suicide ideation, certainly, there are other factors that also suicide ideation risk. At least, one study suggests that poor family cohesiveness could possibly be a suicide ideation risk factor (Wong, Uhm, \& Li, 2012). Negative perceptions about oneself can be a relevant factor in suicidal thoughts. Psychological turmoil is one if not the strongest predictor of suicide ideation and suicide attempts. Shneidman's model of suicide ideation seems to provide a clue on what triggers suicidal thoughts. The previous study found out that psychache or psychological pain (Shneidman, 1993) was found to have had a significant link with suicide ideation (Troister, Davis, Lowndes, \& Holden, 2013). Recent findings seem to strengthen the contention on the relation between psychache and suicide ideation. Montemarano, Troister, Lambert, and Holden (2018) argued that all factors are relevant to suicide ideation only if they linked through psychache. If this contention can be held true, then psychological pain is the strongest determining factor of suicide ideation. However, although previous findings shed light on the nature and relevant factors of depression, one problem remains. To date, identifying symptoms of depression and suicidal ideation remains a grand challenge for mental health professionals. This study argues that knowing the driving factors of psychological problems is one thing; identifying them is another.

\subsection{Current study}

As mentioned, influential factors of depression and suicide ideation are almost clear. The remaining problem, as most mental health professionals had found in the process of identifying signs of depression and suicide ideation. The main purpose of this study, therefore, is to identify the sign of depression and suicide ideation embedded in personal writing using text analysis. Because this technique focuses on words that are directly or indirectly linked to depression and suicidal ideation, social desirability and other response biases were minimized. This paper further argued that personal writing could provide clues of depression and suicidal ideation. Hence, the primary focus of this inquiry was to analyze the personal writings of college students. This study may be the first to use text analysis specifically LIWC in the Philippine setting in identifying words associated with depression and suicide ideation. The result of this endeavor will be of great help to mental health interventions by providing keys to identifying signs of psychological problems. 


\section{Method}

\subsection{Design}

This study used correlational research design in determining the relationship and predictive ability of LIWC domains on depression and suicidal ideation. Each variable was measured using the following assessment tools.

Linguistic Inquiry and Word Count (LIWC) - The online version of LIWC was used to analyze the personal writings of the participants. It is a software that calculates the number of words, and grouped them in several psychological categories. This program identifies the number of important words from personal writings and groups them into two main categories. The first one is the Traditional LIWC dimension which reflects the percentage of words present in each dimension. Under this category, there are five dimensions which include I-Words (I, Me, My), Social Words, Positive Emotions, Negative Emotions, and Cognitive Processes. Because the output was in percentage, the number of words in each dimension was identified by multiplying the percentage from the total number of words that each participant was written.

The second major category is the Summary Variables. This category has four domains which include Analytic, Clout, Authenticity, and Emotional Tone. The analytic domain pertains to formal thinking; clout pertains to authoritativeness, confidence, and leadership capabilities; authenticity refers to the truthfulness of the writing; emotional tone refers to the emotional state of the participant based on the rated text. Unlike the traditional dimension, each domain of the summary variables uses a 100 -point scale $(0=$ Low, $100=$ High $)$ to determine the level of each domain.

Beck's Depression Inventory (BDI) - The freshmen students' academic adjustment was measured using Beck's Depression Inventory (Beck, Ward, Mendelson, Mock, \& Erbaugh, 1961). It is a 21-item questionnaire that has a 4-point scale. The total score is the sum of all scores of all items which determine the level of depression (1-10 = The ups and downs are considered normal; 11-16 = Mild mood disturbance; 17-20= Borderline clinical depression; 21-30 = Moderate depression; 31-40 = Severe depression; over $40=$ Extreme depression). Beck, Steer and Carbin (1988) reported an acceptable internal consistency for the scale $(\alpha=.81)$ for non-psychiatric participants. In the present study, BDI shows higher internal consistency $(\alpha=.87)$.

Suicidal Ideation Attributes Scale (SIDAS) - To measure the participants' suicide ideation, the Suicidal Ideation Attributes Scale (Van Spijker et al., 2014) was used. This scale has five items that assess the suicide ideation of the participants. Each item was scored using a 10-point scale. It has a reported internal consistency of $(\alpha=.91)$. In this study, SIDAS also yielded higher internal consistency $(\alpha=.94)$.

\subsection{Participants}

There were 176 second-year psychology students of Central Luzon State University participated in this study. However, the initial examination of the data revealed some missing values and inconsistencies that could negatively affect the outcome of the analysis. To obtain cleaner data, 17 participants who had incomplete responses (and other irregularities) were discarded from the data set. Only 159 participants were included in this study with age ranging from $19-23$ years old $(M=18.87, S D=.83)$.

Prior to the data gathering, the proposed topic underwent a review by the Institutional Review Board (IRB) in the university to make sure that all ethical standards and considerations were taken into consideration. Upon receiving the permission to proceed, the data gathering immediately commenced. The data gathering had two parts. First, the participants were instructed to respond to Beck's Depression Inventory and the Suicide Ideation Attributes Scale. The first step was conducted in a classroom environment were students could comfortably respond to the questionnaires. After completed the questionnaires, the participants were then instructed to do the second part which was essay writing. They were told to write an essay about their current emotional feelings in 
the English language. The essay has a minimum 100 words and a maximum of 500 hundred words (this is due to the limitation of the online version of LIWC). To give the participants enough time to contemplate, the researcher allowed them to bring the task home. The finished essays were submitted via email several days later. The participants who completed the tasks were given extra credits.

\subsection{Ethical considerations}

No participant in this study was forced to respond to the questionnaires and write the essay. In the same manner, this study did not cause any emotional or psychological uneasiness to the participants. All participants were given the freedom to withdraw from participating in the study before, during, and after the data gathering process. Anonymity and confidentiality were both assured.

\subsection{Data analyses}

The Pearson Moment Correlation was used in analyzing the relationship between the Traditional LIWC Dimensions, Summary Variables, depression level, suicidal ideation, and the total number of words. Stepwise regression analyses were conducted to determine the best predictor domains of Traditional LIWC Dimensions and Summary Variables on depression and suicide ideation.

\section{Results}

This study aimed to identify signs of depression and suicidal ideation from personal writings. Using the Linguistic Inquiry and Word Count (LIWC) results in traditional dimensions and summary variables were correlated with depression and suicidal ideation. Important findings are indicated in the following tables.

\section{Table 1}

Relationship between traditional LIWC dimensions, summary variables, words of the essay and BDI with SIDAS

\begin{tabular}{|c|c|c|c|c|}
\hline \multirow{2}{*}{ Items } & \multicolumn{2}{|c|}{ BDI } & \multicolumn{2}{|c|}{ SIDAS } \\
\hline & $r$ & $p$ & $r$ & $p$ \\
\hline \multicolumn{5}{|l|}{ Traditional LIWC Dimensions } \\
\hline I-Words (I, Me, My) & $.289 * *$ & .000 & $.202 *$ & .011 \\
\hline Social Words & .028 & .727 & .023 & .771 \\
\hline Positive Emotions & -.105 & .186 & -.121 & .13 \\
\hline Negative Emotions & $.280 * *$ & .000 & .142 & .075 \\
\hline Cognitive Processes & .131 & .100 & .099 & .212 \\
\hline \multicolumn{5}{|l|}{ Summary Variables } \\
\hline Analytic & -.078 & .328 & -.010 & .899 \\
\hline Clout & $-.213 * *$ & .007 & $-.166^{*}$ & .037 \\
\hline Authenticity & .093 & .242 & .041 & .611 \\
\hline Emotional Tone & $-.295^{* *}$ & .000 & $-.213 * *$ & .007 \\
\hline Total Number of Words of the Essay & $.166 *$ & .036 & .147 & .065 \\
\hline
\end{tabular}

Note. ${ }^{*} p<.05, * * p<.01, * * * p<.001$.

The correlational analysis in table 1 revealed some modest but significant findings. First, out of five traditional LIWC dimensions, only the number of I-words used $(r=.289, p=.000)$ and negative emotions $(r$ $=.280, p=.000)$ shown significant relationship with depression. With SIDAS, however, only I-words was significantly correlated $(r=.202, p=.011)$.

Second, of four summary variables, only two had consistent significant correlation with depression and suicide ideation. Clout was significantly linked with depression $(r=-.213, p=.007)$ and suicide ideation $(r=$ $-.166, p=.037)$. Likewise, emotional tone also shown significant relationship with depression $(r=-.295, p$ $=.000)$ and suicidal ideation $(r=-.213, p=.007)$. Lastly, the total number of words of the essay was significantly correlated with depression $(r=.166, p=.036)$. 


\section{Table 2}

Regression analysis on the influence of traditional LIWC dimensions on depression and suicidal ideation

\begin{tabular}{|c|c|c|c|c|c|c|}
\hline \multirow{2}{*}{ Traditional LIWC Dimension } & \multicolumn{3}{|c|}{ BDI } & \multicolumn{3}{|c|}{ SIDAS } \\
\hline & $B$ & $S E B$ & $\beta$ & $B$ & $S E B$ & $\beta$ \\
\hline \multicolumn{7}{|l|}{ Step 1} \\
\hline Constant & 15.721 & 1.648 & & 5.385 & 2.262 & \\
\hline I-Words & .151 & .040 & $.29 * *$ & .142 & .055 & $.202 *$ \\
\hline$R^{2}$ & .084 & & & .041 & & \\
\hline$F$ & $14.346^{* *}$ & & & $6.653^{*}$ & & \\
\hline \multicolumn{7}{|l|}{ Step 2} \\
\hline Constant & 17.661 & 1.603 & & 7.646 & 2.242 & \\
\hline I-Words & .277 & .046 & $.53 * *$ & .288 & .065 & $.410 * *$ \\
\hline Positive Emotions & -.572 & .122 & $-.413^{* *}$ & -.666 & .171 & $-.359 * *$ \\
\hline$R^{2}$ & .197 & & & .126 & & \\
\hline$F$ & $19.110 * *$ & & & $11.249 * *$ & & \\
\hline$\Delta R^{2}$ & .113 & & & .085 & & \\
\hline$\Delta F$ & 21.959 & & & 15.241 & & \\
\hline \multicolumn{7}{|l|}{ Step 3} \\
\hline Constant & 16.859 & 1.639 & & & & \\
\hline I-Words & .223 & .053 & $.425^{* *}$ & & & \\
\hline Positive Emotions & -.579 & .121 & $-.418 * *$ & & & \\
\hline Negative Emotions & .246 & .125 & $.177 *$ & & & \\
\hline$R^{2}$ & .217 & & & & & \\
\hline$F$ & $14.279 * *$ & & & & & \\
\hline$\Delta R^{2}$ & .020 & & & & & \\
\hline$\Delta F$ & 3.905 & & & & & \\
\hline
\end{tabular}

In table 2, the predictive ability of the Traditional LIWC Dimensions on depression and suicide ideation was tested using stepwise regression. The result shows important unique findings. Out of five traditional LIWC dimensions, only three were significant predictors (I-words, positive emotions, and negative emotions) and when combined yielded a significant influence on depression $(F(3,155)=14.279, p=.000)$.

As indicated in the table, the I-words domain was found to be a significant predictor on depression $\left(\Delta R^{2}=.084\right.$, $F(1,157)=14.346, p=.000)$. About $8.4 \%$ of the depression variance can be attributed to I-words which is a significant predictor of depression $(\beta=.29)$. The Positive emotions dimension was found to be the second significant predictor $(\beta=-.413, \mathrm{p}=.000)$ which increased the variance of depression by $11.3 \%$ making it the second significant predictor of depression $\left(\Delta R^{2}=.113, F(1,156)=21.959, p=.000\right)$. The last significant predictor was negative emotions which potentially influenced the depression variance by $2.0 \%$. Although modest, negative emotions significantly influenced depression $\left(\Delta R^{2}=.020, F(1,155)=3.905, p=.050\right)$ and a potential predictor $(\beta$ $=.177, p=.050)$.

Table 2 also shows the predictive ability of the Traditional LIWC dimensions on suicide ideation. Out of five domains, only two were significant predictors (I-words and positive emotions domains) which had the significant predictive ability $(F(1,156)=11.249, p=.000)$.

The I-words domain was found to be a significant predictor of suicidal ideation $(\beta=.202, \mathrm{p}=.011)$ and potentially influenced the variance of suicidal ideation by $4.1 \%\left(\Delta R^{2}=.041, F(1,157)=6.653, p=.011\right)$. Positive emotions domain was also found to have a predictive ability on suicidal ideation $(\beta=-.359, p=.000)$ and influenced the suicide ideation variance by $8.5 \%\left(\Delta R^{2}=.085, F(1,156)=15.241, p=.000\right)$. 


\section{Table 3}

Regression analysis on the influence of LIWC summary variables on depression and suicidal ideation

\begin{tabular}{|c|c|c|c|c|c|c|}
\hline \multirow{2}{*}{ LIWC Summary Variables } & \multicolumn{3}{|c|}{ BDI } & \multicolumn{3}{|c|}{ SIDAS } \\
\hline & $B$ & $S E B$ & $\beta$ & $B$ & $S E B$ & $\beta$ \\
\hline \multicolumn{7}{|l|}{ Step 1} \\
\hline Constant & 24.312 & 1.093 & & 13.519 & 1.499 & \\
\hline Emotional Tone & -.091 & .024 & $-.295 * *$ & -.089 & .032 & $-.213 * *$ \\
\hline$R^{2}$ & .087 & & & .045 & & \\
\hline$F$ & $14.925 * *$ & & & $7.449 * *$ & & \\
\hline \multicolumn{7}{|l|}{ Step 2} \\
\hline Constant & 25.720 & 1.211 & & & & \\
\hline Emotional Tone & -.087 & .023 & $-.279 * *$ & & & \\
\hline Clout & -.100 & .040 & $-.190 *$ & & & \\
\hline$R^{2}$ & .123 & & & & & \\
\hline$F$ & $10.895 * *$ & & & & & \\
\hline$\Delta R^{2}$ & .036 & & & & & \\
\hline$\Delta F$ & 6.355 & & & & & \\
\hline
\end{tabular}

The table 3 indicates the results of the stepwise regression analysis on the predictive ability of LIWC summary variables on depression and suicide ideation. Out of four variables, only two (emotional tone and clout) were identified as significant predictors of depression $(F(2,156)=10.895, p=.000)$. Individually, emotional tone might influence depression's variance by $8.7 \%\left(\Delta R^{2}=.087, F(1,157)=14.925, p=.000\right)$ making it a significant predictor on depression $(\beta=-.295, p=.000)$. Likewise, clout also contributed to the variance of depression by $3.6 \%\left(\Delta R^{2}=.036, F(1,156)=6.355, p=.013\right)$. However, out of four summary variables, only emotional tone was a significant predictor of suicidal ideation $(F(1,157)=7.449, p=.007)$. Although only $4.5 \%$ of the variance of suicidal ideation can be attributed to emotional tone, it is a highly significant predictor $(\beta=-.213$, $p=.007)$.

\section{Discussions}

The main purpose of this study was to fill the gap in the literature in identifying signs of depression and suicidal ideation in personal writings. This study found important findings that could help mental health professionals to identify depression individuals using text analysis. The main findings and implications of the results are discussed.

\subsection{The relationship between LIWC dimensions and depression with suicide ideation}

The result shows that out of five traditional LIWC dimensions (I-words, social words, positive emotions, negative emotions, cognitive processes), only I-words and negative emotions dimensions were found to have a modest but significant link with depression. The findings may suggest two interesting points. First, the use of personal pronouns in personal writing may suggest psychological states inherent in the writer's inner experience. Although modest in strength, the correlation results provide a promising way of understanding depression. Certainly, the findings need further verification. However, it might be plausible to assume that depression can be seen by seeing the invisible cues embedded in the person's written language. The present result corroborates previous studies that show the significant association between depression and personal pronouns (Bernard, Baddeley, Rodriguez, \& Burke, 2015; Brockmeyer, et al., 2015). In addition, the finding of this study supports the contention of Pennebaker, Mehl, and Niederhoffer (2003) which suggests that psychological states can be identified through the individuals' written words. However, the result did not account for the possible methodological flaws of the study.

One of the weaknesses of the finding stems from the data gathering procedure wherein participants were instructed to write an essay about their current personal emotional feeling. The essays, would, of course, pertain 
to the personal account and therefore would more likely to produce personal pronoun words or I-words. However, the current finding may somehow show that, even in a collectivist culture, the use of personal pronouns is eminent in those with psychological turmoil. Do people in different cultural and social contexts follow a similar pattern in writing when experience depression? This may be another question that deserves future scientific inquiry. Furthermore, this finding adds support to the existing evidence which shows the possible application of text analysis in identifying the hidden themes of psychological issues in personal writings often missed by traditional assessment tools.

Secondly, the negative emotions dimension also shows a highly significant relationship with depression. Although it is not surprising, this finding somehow strengthens the assumption that the LIWC detects psychological states. In this case, the number of words related to negative emotions was found to have a significant relationship with depression. Again, because this might be the first to use LIWC in analyzing personal writings in the Philippine setting, future research endeavors may be needed to verify the current finding. Nonetheless, this study somehow provides a new window for clinicians and mental health professionals in determining signs of depression in a whole new way. If the findings of this study can be held ubiquitous, therefore, the present results can be used in other social and cultural contexts.

On suicide ideation, however, only the number of personal pronouns (I-words) was significantly correlated. The finding further suggests that personal pronouns may also a sign of suicide ideation. The more personal pronouns found in personal writing, the more likely the writer experience suicidal thoughts. This might be the first study that used LIWC in identifying suicidal ideation cues. Like depression, suicide ideation is often concealed and often undetected by traditional assessment tools. Using text analysis especially LIWC may be of great help in unraveling mental health issues. Personal pronouns are indicative of both depression and suicidal ideation. This study does not only shed new light on clinical practice but also in formulating preventive actions.

Moreover, out of four LIWC summary variables, clout and emotional tone were the only domains significantly correlated with depression. The finding may imply that depressed individuals may show low authority related words in their writing. This is reflected in the negative correlation between clout and depression. At least one study seemed to provide a vital clue. Pudrovska and Karraker (2014) contend that depressive symptoms were high among women with job authority than those without job authority. The reason behind, as the previous authors argued, was the cultural sense of femininity and masculinity. In this study, however, it is not clear whether a similar explanation is possible. Context wise, previous studies focused heavily on job authority and not the sense of authoritativeness depicted by the clout domain of LIWC. To this point, the result of the present study could only show statistical significance but the explanation remains dearth. Future research on this field may further clarify latent factors that could provide a meaningful explanation.

The same result found between emotional tone and suicidal ideation. Emotional tone refers to the emotional state of the writer reflected in personal writing. As the result suggests, individuals with suicidal thoughts showed lower scores on the emotional tone domain. This might support the existing empirical evidence which suggests that expressive writing helps improve psychological health (Niles, Haltom, Mulvenna, Lieberman, \& Stanton, 2014). As the college student wrote their essay about their current emotional state, their emotional turmoil might have decreased over the course of the whole writing process. As depression level dwindles, suicidal thoughts associated with depression might have also decreased.

Another interesting result of this study suggests that the length of personal writing was significantly correlated with depression. Although it was low, a significant relationship may suggest that depressed individuals tend to write longer when describing their emotional state. To the knowledge of the author, this is the first effort to document the association between length of personal writing and depression. Apart from using computerized tools to unravel depression cues in personal writings, looking at the actual length of the essay or any written language may already provide clues. But how long personal writing becomes indicative of depression? This question is beyond the scope of this study. The participants of this study were instructed to write a 100-500-word 
essay about their current emotional feelings. Setting a minimum and maximum amount of words was primarily due to the limitation of the online LIWC version. Lower than 50 words, as the guideline of the online version, indicates, may not yield an accurate result. Since the online version only reads the first 500 words of the text, the maximum number of words was set. This paper, however, suspects that, while minimum and maximum word requirement for the essay was important in the study, it too could detriment the accuracy of the statistical result. Two things might have happened. First, participants were forced to write a hundred words longer than they would willingly write. Second, participants who would have written longer essays were constrained and therefore forced to limit the length of the essay. Both cases may have had affected the obtained data and the statistical result as well. Future research on this topic may try to allow participants to write an essay freely. This study also recommends the use of the paid version of LIWC.

\subsection{The influence of LIWC traditional dimensions on depression and suicidal ideation}

The influence of traditional dimensions on depression and suicidal ideation was assessed. The finding suggests that personal pronouns (I-words), positive and negative emotions significantly predicted depression. Consistent with the correlation result, depressed individuals tend to write more personal pronouns than those with lower depression levels. This strengthens the assumption that I-words could be, indeed, the sign of depression. This assumption, however, needs to be verified and owes future research undertaking. Nonetheless, the present finding corroborates with the previous contention of Chung and Pennebaker (2007) which stated that regular words used in daily communication reflect the individual's psychological states. This finding may be tremendously helpful in psychological science in general and in mental health in particular. As suggested in the result, the number of personal pronouns embedded in an essay may divulge psychological states, in this case, depression.

Negative and positive emotions, on the other hand, had different trajectories on their influence on depression. Words that pertain to positive emotions had shown a negative influence on depression and words associated with negative emotions positively influenced depression. This is not surprising because most empirical evidence had already paved an explanation. Happy people have a lower tendency to get depressed than lonely people. What is unique in this finding, however, is the employed method. Unlike most studies in this area, the present findings were found using a unique way of understanding and identifying signs of depression. This might imply two things. First, it is possible to peek into the person's psychological experiences by analyzing his/her written language. Second, the findings may be indicative of the effectiveness of LIWC in determining and labeling signs of depression in written language.

On the other hand, with suicidal ideation, only I-words (personal pronouns) and positive emotion-related words significantly predict suicidal ideation. Personal writings of individuals with suicidal ideation seemed to contain more personal pronouns and fewer words that connote positive emotions. A straight forward implication would be that college students with suicidal thoughts tend to include more personal pronouns in their essays. If Chung and Pennebaker (2007) were right, the inclusion of I-words in the students' essay was not intentional. Rather, it might appear to be a natural process wherein an individual is unaware of. The most important contribution of this study resides in the fact that the findings of the present investigation were not drawn from traditional assessment tools unlike the previous studies on depression and suicide ideation in the Philippine setting (Sta. Maria, Lee, Estanislao, Rodriguez, Wang, \& Liu, 2015; Quintos, 2017; Estrada, et al., 2019). This paper does not discriminate traditional assessment tools on depression and suicidal ideation. But rather to suggest a new way of understanding and examining psychological problems. Again, the finding of this study may suggest the importance of personal writing in assessing psychological problems.

\subsection{The influence of LIWC summary variables on depression and suicidal ideation}

The results suggest that emotional tone and clout were significantly predicted depression. As individuals get more depressed, they tend to show less emotional tone in their writing. Likewise, as individuals get depressed, 
their writings may contain less sense of authoritativeness. Although the influence of both factors on the variance of depression was small, the findings may have a significant implication and contribution to the field of mental health. With the lack of previous studies in this area, this paper could only provide a naive piece of explanation. As discussed above, the main possible reason as to why personal writings of depressed people tend to indicate less emotional tone is due to the positive effect of the writing process on the psychological state (Niles et al., 2014). In effect, decreasing the level of depression associated with essay writing may be the positive effect of expressive writing.

Lastly, the result suggests that with all the LIWC summary variables, the only emotional tone had shown a significant link with suicidal ideation. The trajectory of the influence on the suicidal ideation variance might imply that individuals with a high tendency of having suicidal thoughts tend to have less emotional tone in personal writing. It could be that; expressive writing would somehow help lessen the participants' negative thoughts. Ultimately, writing current emotional feelings could improve well-being and psychological health.

\section{Conclusion}

Despite the observed weaknesses and limitations, this study conveys important and significant findings. First, using the LIWC tool, college students with a higher level of depression and suicidal ideation tend to include more personal pronouns such as "I", "me", and "my" in their writing when instructed to write their current emotional feelings. Secondly, two out of five LIWC traditional dimensions (I-words and negative emotions) show a significant link with depression but only the I-words dimension was significantly correlated with suicidal ideation. Third, out of four LIWC summary variables, only clout and emotional tone show a negative but significant relationship with depression and suicidal ideation. These LIWC domains were also found to be significant predictors of depression. However, the only emotional tone was found to have a modest but significant influence on suicidal ideation. Lastly, the length of the essay was significantly correlated with depression but not with suicidal ideation.

\subsection{Limitations and recommendations for future studies}

Interpreting the result of this study should involve some caution. Although the results draw tantalizing conclusions, this paper has statistical and methodological limitations. The first weakness, as you might already know, stems from the correlational design. Issues in the statistical analysis used may weaken the ability of the result to provide a stronger proposition. Second, on the methodological aspect, it is worth remembering that the essay writing and questionnaire administration did not occur simultaneously. The participants were given several days to complete their writing. Taking this into consideration, college students might have experienced different psychological states throughout the process. Also, the administration of the questionnaire was during the final examination week of the semester. Also, most of the participants wrote their essays after the final exam. This may imply two things. First, since the scales were administered during the exam week, academic pressure and stress may have played a significant role in students' psychological state which then affected their reported depression and suicidal ideation level. Second, if most of the participants wrote their essay after the exam, the level of stress that was related to depression measured may have somehow sublimed. These factors should be brought into consideration for future research in this area.

Nonetheless, this study provides a new breed of information not only for the scientific community but also for mental health professionals. This may be the first endeavor to unravel the signs of depression and suicidal ideation in the Philippines using text analysis. This paper also suggests that using a text analysis tool can identify students with psychological turmoil and help them heal. 
Acknowledgment: The author would like to send a million thanks to the Ethics Review Board for the ethical guidance that was followed and supported by this inquiry. Furthermore, the author would like to express his gratitude to all the students who willingly share their time in participating in this study.

\section{References}

Beck, A. T., Steer, R. A., \& Carbin, M. G. (1988). Psychometric properties of the Beck Depression Inventory: Twenty-five years of evaluation. Clinical Psychology Review, 8(1), 77-100. https://doi.org/10.1016/0272-7358(88)90050-5

Beck, A.T., Ward, C. H., Mendelson, M., Mock, J., \& Erbaugh, J. (1961). An inventory for measuring depression. Archives of General Psychiatry, 4, 561-571.

Bernard, J. D., Baddeley, J. L., Rodriguez, B. F., \& Burke, P. A. (2015). Depression, language, and affect: An examination of the influence of baseline depression and affect induction on language. Journal of Language and Social Psychology, 35(3), 317-326. https://doi.org/10.1177/0261927X15589186

Boroditsky, L. (2001). Does language shape thought?: Mandarin and English speakers' conceptions of time. Cognitive Psychology, 43(1), 1-22. https://doi.org/10.1006/cogp.2001.0748

Boyd, R. L., \& Pennebaker, J. W. (2015). Did Shakespeare write double falsehood? Identifying individuals by creating psychological signatures with text analysis. Psychological Science, 26(5), 570-582. https://doi.org/10.1177/0956797614566658

Brockmeyer, T., Zimmermann, J., Kulessa, D., Hautzinger, M., Bents, H., Friederich, H. C., ... \& Backenstrass, M. (2015). Me, myself, and I: self-referent word use as an indicator of self-focused attention in relation to depression and anxiety. Frontiers in Psychology, 6(1564), 1-10. https://doi.org/10.3389/fpsyg.2015.01564

Castillo, L. G., \& Schwartz, S. J. (2013). Introduction to the special issue on college student mental health. Journal of Clinical Psychological, 69(4), 291-297. https://doi.org/10.1002/jclp.21972

Chen, C. J., Chen, Y. C., Sung, H. C., Hsieh, T. C., Lee, M. S., \& Chang, C. Y. (2015). The prevalence and related factors of depressive symptoms among junior college nursing students: A cross-sectional study. Journal of Psychiatric and Mental Health Nursing, 22, 590-598. https://doi.org/10.1111/jpm.12252

Chung, C. k., \& Pennebaker, J. W. (2007). The Psychological functions of function words. In K. Fiedler (Ed.), Frontiers of social psychology. Social communication (p. 343-359). Psychology Press.

Cichocka, A., Bilewicz, M., Jost, J. T., Marrouch, N., \& Witkowska, M. (2016). On the grammar of politics—or why conservatives prefer nouns. Political Psychology, 37(6), 799-815. https://doi.org/10.1111/pops.12327

Coskun, O., Ocalan, A. O., Ocbe, C. B., Semiz, H. O., \& Budakoglu, I. (2019). Depression and hopelessness in pre- clinical medical students. The Clinical Teacher 16, 345-351.

Dahlin, M., Joneborg, N., \& Runeson, B. (2005). Stress and depression among medical students: A cross-sectional study. Medical Education, 39(6), 594-604. https://doi.org/10.1111/j.1365-2929.2005.02176.x

Delfabbro, P. H., Malvaso, C., Winefield, A. H., \& Winefield, H. R. (2015). Socio-demographic, health, and psychological correlates of suicidality severity in Australian adolescents. Australian Journal of Psychology, 68(4), 261-269. https://doi.org/10.1111/ajpy.12104

Dunn, M. S., Goodrow, B., Givens, C., \& Austin, S. (2008). Substance use behavior and suicide indicators among rural middle school students. Journal of School Health, 78(1), 26-31.

Ediz, B., Ozcakir, A., \& Bilgel, N. (2017). Depression and anxiety among medical students: Examining scores of the beck depression and anxiety inventory and the depression anxiety and stress scale with student characteristics. Cogent Psychology, 4(1). https://doi.org/10.1080/23311908.2017.1283829

Estrada, C. A. M., Nonaka, D., Gregorio, E. R., Jr. Leynes, C. R., del Castillo, R. T., Hernandez, P. M. R., ... \& Kobayashi, J. (2019). Suicidal ideation, suicidal behaviors, and attitudes towards suicide of adolescents enrolled in the alternative learning system in Manila, Philippines: A mixed methods study. Tropical 
Medicine and Health, 47(22), 1-18. https://doi.org/10.1186/s41182-019-0149-6

Garlow, S. J., Rosenberg, J., Moore, J. D., Haas, A. P., Koestner, B., Hendin, H., \& Nemeroff, C. B. (2008). Depression, desperation, and suicidal ideation in college students: Results from the American Foundation for Suicide Prevention College Screening Project at Emory University. Depression and Anxiety, 25(6), 482-488. https://doi.org/10.1002/da.20321

Horgan, A., Sweeney, J., Behan, L., \& McCarthy, G. (2016) Depressive symptoms, college adjustment and peer support among undergraduate nursing and midwifery students. Journal of Advanced Nursing 72(12), 3081-3092. https://doi.org/10.1111/jan.13074

Jordan, K. N., Sterling, J., Pennebaker, J. W., \& Boyd, R. L. (2019). Examining long-term trends in politics and culture through language of political leaders and cultural institutions. Proceedings of the National Academy of Sciences, 116(9), 3476-3481.

Kacewicz, E., Pennebaker, J. W., Davis, M., Jeon, M., \& Graesser, A. C. (2013). Pronoun use reflects standings in social hierarchies. Journal of Language and Social Psychology, 33(2), 125-143. https://doi.org/10.1177/0261927X13502654

Kuo, E. S., Stoep, A. V., Herting, J. R., Grupp, K., \& McCauley, E. (2013). How to identify students for school-based depression intervention: Can school record review be substituted for universal depression screening? Journal of Child and Adolescent Psychiatric Nursing, 26(1), 42-52. https://doi.org/10.1111/jcap.12010

Lamis, D. A., Ballard, E. D., May, A. M., \& Dvorak, R. D. (2016). Depressive symptoms and suicidal ideation in college students: The mediating and moderating roles of hopelessness, alcohol problems, and social support. Journal of Clinical Psychology, 72(9), 919-932. https://doi.org/10.1002/jclp.22295

Maniam, T., Chinna, K., Lim, C. H., Kadir, A. B., Nurashikin, I., Salina, A. A., Mariapun, J. (2013). Suicide prevention program for at-risk groups: Pointers from an epidemiological study. Preventive Medicine, 57, S45-S46. https://doi.org/10.1016/j.ypmed.2013.02.022

Montemarano, V., Troister, T., Lambert, C. E., Holden, R. R. (2018). A four-year longitudinal study examining psychache and suicide ideation in elevated-risk undergraduates: A test of Shneidman's model of suicidal behavior. Journal of Clinical Psychology, 74(10), 1820-1832. https://doi.org/10.1002/jclp.22639

Newman, M. L., Pennebaker, J. W., Berry, D. S., \& Richards, J. M. (2003). Lying words: Predicting deception from linguistic styles. Personality and Social Psychology Bulletin, 29(5), 665-675. https://doi.org/10.1177/0146167203029005010

Niles, A. N., Haltom, K. E., Mulvenna, C. M., Lieberman, M. D., \& Stanton, A. L. (2014). Effects of expressive writing on psychological and physical health: The moderating role of emotional expressivity. Anxiety Stress Coping, 27(1), 1-19.

Nyer, M., Farabaugh, A., Fehling, K., Soskin, D., Holt, D., Papakostas, G. I., .. \& Mischoulon, D. (2013). Relationship between sleep disturbance and depression, anxiety, and functioning in college students. Depression and Anxiety, 30(9), 873-880. https://doi.org/10.1002/da.22064

Pennebaker, J. W., Chung, C. K., Frazee, J., Lavergne, G. M., \& Beaver, D. I. (2014). When small words foretell academic success: The case of college admissions essays. PLoS ONE, 9(12), 1-10. https://doi.org/10.1371/journal.pone.0115844

Pudrovska, T., \& Karraker, A. (2014). Gender, job authority, and depression. Journal of Health and Social Behavior, 55(4) 424-441. https://doi.org/10.1177/0022146514555223

Puthran, R., Zhang, M. W. B., Tam, W. W., \& Ho, R. C. (2016). Prevalence of depression amongst medical students: A meta-analysis. Medical Education, 50(4), 456-468. https://doi.org/10.1111/medu.12962

Quintos, M. A. M. (2017). Predictors of suicide ideation among the Filipino youth: Findings from a nationally representative survey of Filipinos aged 15 to 27. Journal of Multidisciplinary Studies, 6(2), 1-26.

Quintos, M. A. M. (2017). Prevalence of suicide ideation and suicide attempts among the Filipino youth and its relationship with the family unit. Asia Pacific Journal of Multidisciplinary Research, 5(2), 11-23.

Rotenstein, L. S., Ramos, M. A., Torre, M., Segal, J. B., Peluso, M. J., Guille, C., .. \& Mata, D. A. (2016). Prevalence of depression, depressive symptoms, and suicidal ideation among medical students: A Systematic Review and Meta-Analysis. The Journal of the American Medical Association, 316(21), 
2214-2236.

Shneidman, E. S. (1993). Suicide as psychache. Journal of Nervous and Mental Disease, 181, 145-147.

Sta. Maria, M. A., Lee, R. B., Estanislao, S., Rodriguez, C., Wang, J., \& Liu, Y. (2015). A multivariate analysis of suicide ideation among university students in the Philippines. Asia-Pacific Social Science Review, 15(1), 46-62.

Tam, W., Lo, K., \& Pacheco, J. (2018). Prevalence of depressive symptoms among medical students: Overview of systematic reviews. Medical Education, 53(4), 345-354. https://doi.org/10.1111/medu.13770

Tan, L., Xia, T., \& Reece, C. (2016). Social and individual risk factors for suicide ideation among Chinese children and adolescents: A multilevel analysis. International Journal of Psychology, 53(2), 117-125. https://doi.org/10.1002/ijop.12273

Teismann, T., \& Forkmann, T. (2015). Rumination, entrapment and suicide ideation: A mediational model. Clinical Psychology and Psychotherapy, 24(1), 226-234. https://doi.org/10.1002/cpp.1999

Troister, T., Davis, M. P., Lowndes, A., \& Holden, R. R. (2013). A five-month longitudinal study of psychache and suicide ideation: Replication in general and high-risk university students. Suicide and Life-Threatening Behavior 43(6), 611-620. https://doi.org/10.1111/sltb.12043

Van Spijker, B. A. J., Batterham, P. J., Calear, A. L., Farrer, L., Christensen, H., Reynolds, J., \& Kerkhof, A. J. F. M. (2014). The Suicidal Ideation Attributes Scale (SIDAS): Community-based validation study of a new scale for the measurement of suicidal ideation. Suicide and Life-Threatening Behavior, 44(4), 408-419. https://doi.org/10.1111/sltb.12084

Vaughn, L. A. (2018). Contents of hopes and duties: A linguistic analysis. Frontiers in Psychology, 9(757), 1-13. https://doi.org/10.3389/fpsyg.2018.00757

Wong, Y. J., Uhm, S. Y., \& Li, P. (2012). Asian Americans' family cohesion and suicide ideation: Moderating and mediating effects. American Journal of Orthopsychiatry, 82(3), 309-318. https://doi.org/10.1111/j.1939-0025.2012.01170.x 